\title{
Singapore Paediatric Resuscitation Guidelines 2016
}

\author{
Gene Yong Kwang Ong ${ }^{1}$, MBBS, MRCPCH, Irene Lai Yeen Chan ${ }^{1}$, MBBS, MMed, Agnes Suah Bwee Ng², MBBE, MMed, \\ Su Yah $\underline{C h e w}^{3}$, MBBS, MRCPCH, Yee Hui Mok${ }^{4}$, MBBS, MRCPCH, Yoke Hwee $\underline{C h a n}^{4}$, MBBS, MMed, \\ Jacqueline Soo May Ong ${ }^{5}$, MBBChir, MRCPCH, Sashikumar Ganapathy ${ }^{1}$, MBBchBao, MRCPCH, \\ Kee Chong Ng${ }^{1}$, MBBS, MMed; Paediatric Resuscitation Workgroup (2015-2016), National Resuscitation Council Singapore
}

\begin{abstract}
We present the revised 2016 Singapore paediatric resuscitation guidelines. The International Liaison Committee on Resuscitation's Pediatric Taskforce Consensus Statements on Science and Treatment Recommendations, as well as the updated resuscitation guidelines from the American Heart Association and European Resuscitation Council released in October 2015, were debated and discussed by the workgroup. The final recommendations for the Singapore Paediatric Resuscitation Guidelines 2016 were derived after carefully reviewing the current available evidence in the literature and balancing it with local clinical practice.
\end{abstract}

Keywords: National Paediatric Resuscitation Guidelines, paediatric advanced life support, paediatric basic life support, paediatric resuscitation

\section{INTRODUCTION}

The national paediatric and neonatal guidelines were last reviewed and released in 2011.(1) For this review and update, in addition to a paediatric resuscitation workgroup, a neonatal workgroup was appointed to review and update our national neonatal resuscitation guidelines. The National Resuscitation Council (NRC) paediatric workgroup comprised representations from the spectrum of our local paediatric community - paediatric intensivists, paediatric anaesthetists and paediatric emergency physicians - from both the public and private healthcare sectors.

In October 2015, consensus statements on science and treatment recommendations (COSTR) from the Paediatric Taskforce of the International Liaison Committee on Resuscitation (ILCOR) were released. (2-4) The 'Grading of Recommendations, Assessment, Development and Evaluation' (GRADE) system ${ }^{(5,6)}$ was adopted by ILCOR for evidence and scientific reviews for the CoSTR statements. Our workgroup reviewed these consensus statements, as well as the relevant body of evidence and literature, when updating our national paediatric guidelines. In addition, the workgroup reviewed and deliberated on the 2015 paediatric guidelines from the American Heart Association (AHA) and the European Resuscitation Council (ERC). ${ }^{(7-10)}$ Important references made in the papers were accessed and reviewed. Other relevant documents and papers, where appropriate and indicated, were also reviewed. The final recommendations for the NRC were derived after carefully reviewing the current available evidence in the literature and balancing these recommendations with local clinical practice. Where appropriate, the existing levels of evidence and classes of recommendations are cited in our recommendations.

\section{DEFINITIONS}

A neonate is defined as a patient aged 28 days or less. An infant is a patient aged one year and below. A child is any patient aged one year to puberty. Unless otherwise stated, 'paediatrics' in our recommendations refers both to infants and children, but excludes neonates.

\section{MAIN RECOMMENDATIONS}

Our main recommendations are divided into four sections: pre-arrest paediatric acute care; basic paediatric life support; advanced paediatric life support; and post-arrest paediatric acute care. Each section consists of sub-sections that are expanded upon in the following paragraphs.

\section{A. PRE-ARREST PAEDIATRIC ACUTE CARE Paediatric Early Warning Score}

In-hospital paediatric cardiac and respiratory arrest can potentially be averted by early recognition and intervention for the deteriorating patient. The use of early warning systems might enable identification of such patients so as to initiate effective interventions promptly. These early warning scoring systems assign numeric scores to specific abnormal observations in several clinical domains. Any effective scoring system must be reliable and reproducible. There must also be an appropriate response when the early warning scoring system identifies critical abnormalities.

At present, there remains a lack of consensus on an accepted paediatric scoring system. ${ }^{(11)}$ The Paediatric Early Warning Score (PEWS), which was first proposed in 2006, has been validated in multicentre studies with high sensitivity and specificity. While early warning scores aid in the detection of deterioration in patients, there is less evidence that they improve clinical outcome. In one observational study, PEWS was associated with a reduction in cardiac arrest rate when used in a single hospital with an established medical emergency team system. ${ }^{(12)}$ There is no evidence that the use of PEWS outside of the paediatric intensive care unit (ICU) setting reduces mortality. ${ }^{(5)}$

\footnotetext{
${ }^{1}$ Children's Emergency, ${ }^{2}$ Department of Paediatric Anaesthesia, KK Women's and Children's Hospital, ${ }^{3} \mathrm{C}$ hildren's Emergency, National University Hospital, ${ }^{4} \mathrm{Children's} \mathrm{Intensive}$ Care Service, KK Women's and Children's Hospital, ${ }^{5}$ Department of Paediatrics, National University Hospital, Singapore

Correspondence: Dr Gene Ong Yong Kwang, Senior Consultant, Children's Emergency, KK Women’s \& Children's Hospital, 100 Bukit Timah Road, Singapore 229899. Gene.Ong.Y.K@singhealth.com.sg
} 


\section{Medical emergency team/rapid response team}

Medical emergency and rapid response teams (METs/RRTs) were developed for the urgent assessment of at-risk patients to prevent cardiac or respiratory arrest. These teams may function as the efferent response to the critical afferent early warning score signal.

However, the effectiveness of METs/RRTs in reducing the incidence of cardiac and/or respiratory arrest outside of the ICU setting is inconclusive. ${ }^{(13-15)}$ Most studies demonstrated trends in improving mortality, although they were not statistically significant. The data has been largely observational and was from before-and-after studies, which may have unaccounted or confounding variables. ${ }^{(13-16)}$ Joffe et $\mathrm{al}^{(17)}$ demonstrated the potential for risk of bias or confounding variables by comparing the mortality rate at their institution, which did not initiate or organise a MET/RRT, with that of five published studies (all reviewed by ILCOR). The reduction in mortality at Joffe et al's institution over the same time period was similar to the published results, illustrating the problems of confounding variables and contemporaneous trends. Variables such as the composition of the team, the type of patient, the hospital setting and the confounder of wider 'system benefit' complicate objective analyses. In addition, the outcome measures that were traditionally evaluated - respiratory arrests, cardiac arrests and deaths - are exceedingly rare. Thus, finding statistically significant changes in their rates often requires accumulating years of data.

A study at a single paediatric centre found that the implementation of an RRT (inclusive of an early warning score and MET) had a positive impact on the reduction of critical deterioration, "a proximate outcome metric defined as unplanned transfer to the ICU with noninvasive or invasive mechanical ventilation or vasopressor infusion in the 12 hours after transfer." (16) Studies using a more valid and proximate outcome metric, such as Bonafide et al's critical decision event, ${ }^{(18)}$ may be better able to answer the question of whether METs/RRTs are truly feasible and effective, before strengthening the case for their implementation in the paediatric inpatient setting. Quality improvement methodology could be used to regulate the impact of a series of changes, which include educational processes, documentation review with feedback systems, and modification of other factors that are thought to improve the delivery of care.

\section{Recommendation}

It is reasonable to use PEWS in the in-hospital setting and MET/ RRT systems in facilities where children with high-risk illnesses are cared for in general inpatient units (Class IIb, LOE C-LD). It appears rational that intervening earlier in the course of development of a medical emergency provides greater scope for limiting the harmful effects of that condition and promoting recovery. The decision to use a MET/RRT system should, however, be balanced by the institution's existing resources and capabilities. Training of emergency medical technicians will also need to be addressed so that evidence-based interventions can be brought into play to truncate the deterioration picked up by the early warning systems. Simulation-based MET training exercises have been linked to improved team performance and outcome. ${ }^{(15)}$

\section{B. BASIC PAEDIATRIC LIFE SUPPORT Recognition and assessment of cardiac arrest $\&$ initial management of collapse}

The key aspects for recognition and assessment of cardiac arrest and initial management of collapse in children are listed in Box 1 and Box 2.

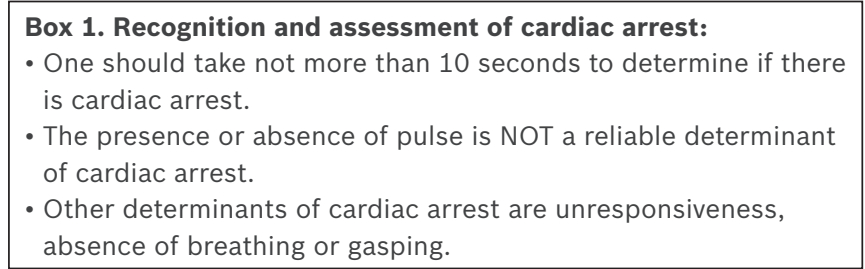

\section{Box 2. Initial management of collapse:}

- One should always ensure the safety of the rescuer(s) and the child at the onset.

- The initial assessment is to check for responsiveness of the child.

- A: If the child is unresponsive, call for help, ask for an ambulance, and get a defibrillator (or an automated external defibrillator [AED]) if it is visible and less than $100 \mathrm{~m}$ away, then open the airway (head tilt-chin lift).

- B: Check for breathing - look, listen and feel for 10 seconds (note that gasping is NOT breathing).

- Check for pulse within the same 10 seconds (optional and for healthcare providers only) - commence cardiopulmonary resuscitation if there is cardiac arrest.

- C: Chest compression should be commenced before giving the initial two rescue breaths.

- If there is only a single rescuer, call for help, ask for an ambulance and get a defibrillator (or an AED) if it is visible and less than $100 \mathrm{~m}$ away, then start chest compressions.

- If an AED is available, check for shockable rhythm and intervene.

There might be some confusion about what A-B-C and $C-A-B$ actually mean and refer to. In the local context, the initial A-B-C refers to opening of the 'airway' (A), checking for 'breathing' (B) and, if absent, followed by 'chest compression' (C), as opposed to other localities, where A-B might refer to 'providing ventilation' (e.g. providing five rescue breaths). Following the initial first compression, A-B then refers to opening the airway and providing rescue breaths (i.e. ventilations), followed again by chest compression (C).

There have been discussions about whether one should do chest compressions first before ventilation or vice versa (i.e. C-A-B vs. A-B-C). There is very low-quality evidence that validates performing chest compression before ventilating a patient. Three simulation-based randomised controlled trials (RCTs) - two adult manikin studies and one paediatric manikin study - which were all downgraded for imprecision and very serious indirectness, ${ }^{(19-21)}$ showed a reduced time to first chest compression using the C-A-B approach, as opposed to the A-B-C approach. Data from the three previously cited RCTs showed that time to first chest compression was 18.0-24.3 seconds shorter when using a C-A-B sequence as compared with an A-B-C 
sequence (15.4-25.0 vs. 36.0-43.4 seconds). Furthermore, data from the two manikin studies showed that time to first ventilation is delayed by only $5.7-6.0$ seconds when using a C-A-B sequence as compared with an A-B-C sequence (28.4-43.0 vs. 22.737.0 seconds). There are no clinical (human) studies comparing the $\mathrm{C}-\mathrm{A}-\mathrm{B}$ and $\mathrm{A}-\mathrm{B}-\mathrm{C}$ approaches for the initial management of cardiac arrest that address outcomes of return of spontaneous circulation (ROSC), survival to hospital admission, or survival to 180 days with good neurological outcome.

As the only trials to date are manikin studies and the ILCOR paediatric taskforce states that "the confidence in effect estimates is so low that the panel decided a recommendation was too speculative", the present workgroup decided to maintain our current practice to open the airway, check for breathing and, if absent, start chest compressions (i.e. A-B-C approach).

\section{Recommendation}

We recommend that for children, one should first open the airway, check for breathing and, if absent, start chest compressions. One should take not more than ten seconds to determine if there is cardiac arrest. The presence or absence of pulse is not a reliable determinant of cardiac arrest. Other determinants of cardiac arrest are unresponsiveness, gasping, not breathing normally and absence of any signs of life.

\section{Compression-ventilation ratio}

In paediatrics, the usual cause of collapse or acute decompensation is respiratory in nature. It is important to optimally manage the respiration and ventilation of a collapsed child. This is different from a collapsed adult, where there is usually an underlying cardiac/dysrhythmia aetiology, and hence the emphasis on optimal chest compression and the use of defibrillation. The workgroup discussed the merits of adhering to the compressionventilation ratio of 30:2 as opposed to 15:2 (i.e. having more interposed ventilations with chest compressions).

One should remember that a 30:2 compression-ventilation CPR ratio is more frequently used by a single rescuer in situations where manpower is limited during the acute resuscitation of a collapsed patient. There have not been any new studies specifically addressing the benefits of a 15:2 vs. 30:2 compression-ventilation ratio for CPR in paediatrics. The general move in resuscitation, especially in healthcare settings, has been to perform continuous effective chest compressions and ventilations with advanced airway devices in situ.

While there is no clear evidence that switching compressors every two minutes improves outcomes, many studies have indicated chest compression decay after two minutes of CPR at 30:2.(22,23) However, one must also remember that the oftquoted two-minute fatigue is derived from studies of trained and seasoned resuscitators. The time to fatigue for laypersons, who are not familiar or well-versed in resuscitation, is likely to be much shorter. In the near future, feedback devices, such as end-tidal carbon dioxide $\left(\mathrm{ETCO}_{2}\right)$ to guide chest compression quality, may help one to better determine the quality of CPR, although these devices will need to be clinically validated.

\section{Recommendation}

For single-rescuer layperson and healthcare providers, we recommend a 30:2 compression-ventilation for children. For healthcare providers with more than one rescuer, we recommend a compression-ventilation ratio of 15:2 when there are no advanced airway devices (i.e. supraglottic devices such as laryngeal mask airway), and continuous chest compressions at 100-120 per minute with interposed ventilations at ten per minute for children with advanced airway devices (see Box 3). The consolidated basic and advanced life support paediatric management algorithm is summarised in Annex A1a and A1b.

\section{Box 3. Compression-ventilation ratio in paediatric basic life support: \\ - Layperson providers: perform 30 compressions followed by 2 ventilations (30:2) for both single rescuers and when a second rescuer is available. \\ - Healthcare providers: perform 30 compressions followed by 2 ventilations (30:2) for single rescuers; when a second rescuer is available, switch to a compression-ventilation ratio of 15:2. \\ - In two-person rescuer CPR, the first rescuer performs compressions and the second rescuer performs ventilations; the compressor role is rotated every 5 cycles to avoid fatigue and the switch should take less than 5 seconds. \\ - Rescuers who are unable or unwilling to provide mouth-to-mouth ventilation are encouraged to perform at least good-quality chest compressions.}

\section{Chest compression depth}

A paediatric (involving patients aged $>1$ year) observational study ${ }^{(24)}$ of in-hospital cardiac arrest (IHCA) (89 cardiac arrest events) showed that chest compression depths $>51 \mathrm{~mm}$ ( $>2$ inches) are associated with statistically significant improvement in outcomes (good neurological outcome: relative risk [RR] 3.71; 95\% confidence interval [Cl] 0.90-15.33; survival to discharge: RR 3.48; 95\% Cl 1.02-11.84), and better survival to 24 hours (adjusted odds ratio [aOR] 10.3; 95\% Cl 2.75-38.8; $\mathrm{p}<0.001$ ) and ROSC (aOR 4.21;95\% Cl 1.34-13.2; $\mathrm{p}=0.014$ ). Two paediatric observational studies ${ }^{(25,26)}$ of IHCA and out-of-hospital cardiac arrest (OHCA), with six and nine subjects, respectively, showed that targeting a real-time measured chest compression depth or a subjective anteroposterior diameter during CPR is not associated with a statistically significant difference in outcome (Sutton et al: OR 1.04; 95\% Cl 0.63-1.71; and Maher et al: RR 6.0; 95\% Cl 1.00-35.91).

As such, ILCOR suggests that "rescuers compress the chests of infants by at least one-third anteroposterior dimension, or approximately 1.5 inches $(4 \mathrm{~cm})$ " and that "rescuers compress the child's chest by at least one-third of the anteroposterior dimension, or approximately 2 inches $(5 \mathrm{~cm})^{\prime \prime}$.

\section{Recommendation}

We recommend that the chest compression depth for paediatric CPR should be at least one-third of the anteroposterior diameter 
Box 4. Chest compression technique for paediatric patients:

- Chest compression technique:

For infants: we recommend the use of the 'two-finger' technique for single-rescuer CPR (this results in less changeover time while maintaining optimal chest compression) and the use of the 'thumb-encircling' technique for CPR by two or more rescuers. For children: we recommend the use of the 'one- or two-hand' technique.

- One should achieve a compression depth of at least one-third of the anteroposterior chest diameter in all children over the lower half of the sternum:

In infants: approximately $4 \mathrm{~cm}$

In children: approximately $5 \mathrm{~cm}$

- PUSH HARD-PUSH FAST at a compression rate of at least 100-120/min.

- There must be complete chest recoil after each compression.

- There must be minimal interruptions (< 5 seconds) to minimise no-flow time.

for infants and children, or approximately $4 \mathrm{~cm}$ to $5 \mathrm{~cm}$, respectively (see Box 4).

\section{Chest compression-only CPR}

Two paediatric observational studies ${ }^{(27,28)}$ looked at the critical outcome of 30-day neurologically intact survival in OHCA ( $n=5,170 ; n=5,056$, respectively), comparing the use of compression-only CPR to conventional CPR. Compression-only CPR was associated with worse 30-day neurologically intact survival (RR 0.46; 95\% Cl 0.34-0.62). Pooled data from the two studies showed no benefit in 30-day neurologically intact survival when comparing the use of bystander compression-only CPR with no bystander CPR (RR 1.21; 95\% Cl 0.89-1.65). For the important outcome of survival to hospital discharge, no paediatric evidence was identified.

Hence, ILCOR recommends that "rescuers provide rescue breaths and chest compressions for paediatric IHCA and OHCA. If rescuers cannot provide rescue breaths, they should at least perform chest compressions (strong recommendation, lowquality evidence)". At present, there is, therefore, no evidence to recommend chest compression-only CPR in acute resuscitation of paediatric patients. However, as stated in Box 3, "Rescuers who are unable or unwilling to provide mouth-to-mouth ventilation are encouraged to perform at least good quality chest compressions."

\section{Recommendation}

We recommend against routine chest compression-only CPR for children. However, rescuers who are unable or unwilling to provide mouth-to-mouth ventilation are encouraged to perform at least good quality chest compressions.

\section{Foreign body airway obstruction (FBAO)}

Infants should have chest thrusts to help dislodge the foreign body. Abdominal thrusts (i.e. Heimlich manoeuvre) are not recommended for infants. Children aged $\geq 1$ year may be given abdominal thrusts (Heimlich manoeuvre) for FBAO care. The algorithm for paediatric FBAO is summarised in Annex A2.

\section{Use of automated external defibrillator in paediatric cardiac arrest}

Since 2005, ILCOR has advocated the early use of automated external defibrillators (AEDs) in children to analyse rhythms and provide defibrillation in cases of cardiac arrest with shockable rhythms. ${ }^{29,30)}$ When recognised early and rapidly treated, paediatric patients with ventricular fibrillation (VF) or pulseless ventricular tachycardia ( $\mathrm{pVT}$ ) have a higher survival rate than those with other rhythms. ${ }^{(31-33)}$ AEDs are capable of accurately identifying arrhythmias in children and are unlikely to advise inappropriate shocks. ${ }^{(34,35)}$ For patients aged $<1$ year, the incidence of shockable rhythms is very low, except when they suffer from cardiac disease. ${ }^{(36)}$

\section{Recommendation}

Paediatric dose-attenuating systems can be used in children aged 1-8 years to reduce the energy dose delivered by AEDs. ${ }^{(29-3)}$ This may be done either via a paediatric-specific (attenuated) pad-cable system, or an AED with a paediatric mode or switch, to select for half of the adult energy dose. Most paediatric-specific attenuation pads deliver 50-75 J (see Box 5).

\section{Box 5. Summary for automated external device (AED) use in children: \\ AED use in children $>\mathbf{8}$ years old \\ - For attempted defibrillation of older children (> 8 years) and teenagers with an AED, the rescuer should use standard AEDs, if available.}

\section{AED use in children 1-8 years old}

- For attempted defibrillation of children aged 1-8 years with an AED, the rescuer should use a paediatric dose-attenuator system (mode or attenuation pads), if available.

- In a child with cardiac arrest, if an AED is available but paediatric dose-attenuator systems are not, the rescuer should use a standard AED.

AED use in infants $>\mathbf{1}$ month old but $<\mathbf{1}$ year old

- For infants (<1 year), a manual defibrillator is preferred.

- If a manual defibrillator or trained rescuers are not available, an AED with paediatric dose-attenuation, if available, should be considered.

- If neither is available, an AED without a dose attenuator may be used.

\section{AED use in infants $<1$ month old}

- For neonates (<1 month), a manual defibrillator is preferred.

- Cardiopulmonary resuscitation should be continued till a manual defibrillator is available.

\section{ADVANCED PAEDIATRIC LIFE SUPPORT}

While pulse check is not recommended for layperson rescuers, healthcare providers may do a pulse check, but this should be carried out during the same ten seconds when the breathing check is being carried out. Pulse should be assessed at the brachial (for infants), femoral (for infants and children) and carotid (for children) arteries.

Newborns that require CPR in any setting should be managed in the same way as newborns in the delivery room, i.e. 3:1 chest 
compression to ventilation ratio. For infants beyond the neonatal period (i.e. $>28$ days of life), CPR should follow the paediatric guidelines, i.e. 30:2 for laypersons and single-rescuer healthcare providers (see Box 3).

\section{Laryngeal mask airway and supraglottic devices}

While paediatric supraglottic devices have been safely used in elective paediatric surgical procedures, their role during emergency situations remains largely consensus-driven. ${ }^{(37)}$ However, early complications are more frequently observed when using supraglottic devices in infants and young children than in adult practice. ${ }^{(38)}$

\section{Prehospital paediatric resuscitation}

Adult OHCA studies have not shown any survival or neurological benefit of bag-valve-mask over the use of supraglottic devices. ${ }^{(39)}$ Observational studies have not found any significant difference in survival among the types of airways used in prehospital paediatric arrest victims ${ }^{(40)}$ or any significant benefits in simulation studies using manikins. ${ }^{(41)}$ In the prehospital environment, based on the limited paediatric literature available, bag-valve-mask should be used for initial airway management. However, if there are issues ventilating a critically ill or collapsed paediatric patient, it is reasonable to use appropriate supraglottic devices, especially laryngeal masks, as a rescue device in conjunction with bag-valve-mask. ${ }^{(37)}$

\section{In-hospital paediatric resuscitation}

While there are no formal high quality studies on supraglottic devices for in-hospital resuscitation of critically ill or collapsed infants and children, supraglottic devices, especially laryngeal mask airways, should be considered for use as rescue airway adjuncts in situations where there is difficulty in intubation and ventilation. Second-generation supraglottic devices may have the added benefits of allowing drainage of gastric contents and facilitation of endotracheal intubation in these situations. ${ }^{(42)}$

\section{Recommendation}

When ventilation is difficult and/or endotracheal intubation is not possible during paediatric resuscitation, appropriate supraglottic airway devices, especially laryngeal mask airways, if available, are recommended when used by experienced providers to provide a patent airway and support ventilation.

\section{Use of atropine for premedication in emergency intubation}

Bradycardia may occur during emergency intubation in the paediatric population. The causes are hypoxia, vagal response to laryngoscopy or pharmacological effect of drugs (e.g. succinylcholine). Bradycardia due to hypoxia is rapidly reversed by effective ventilation. Atropine is generally used to prevent reflex bradycardia during emergency intubation. Observational data suggests that the use of atropine for critical care intubation was associated with a reduction in ICU mortality in children over one month old and reduces the prevalence of new arrhythmias during intubation for children older than one month. ${ }^{(43)}$ However, current evidence, based on observational studies, is not robust regarding the routine use of atropine in emergency intubation for preventing bradycardia or cardiac arrest. $^{(44-47)}$

Recent discussions and studies have also disproved the concept of paradoxical bradycardia below the $0.1 \mathrm{mg}$ dose threshold of atropine. ${ }^{(48,49)}$ Atropine should be administered based on dose-weight requirements, especially for very light-weight premature infants.

\section{Recommendation}

Atropine $(0.02 \mathrm{mg} / \mathrm{kg})$ may be used as premedication in emergency intubations where there is a risk of bradycardia, e.g. when succinylcholine is used to facilitate intubation. There is no absolute minimum dose of atropine and its dosage should be guided by the weight of the patient.

\section{Fluid management}

Fluid management forms a critical part of the resuscitation of a child. When a child shows signs of circulatory compromise caused by reduced circulatory volume or hypovolaemia, controlled volume resuscitation is immediately indicated. ${ }^{(50)}$ However, fluid bolus may not be indicated in children with febrile illness who are not showing signs of reduced circulatory volume or hypovolaemia. A cautious approach to fluid therapy with frequent reassessment of the child is essential. ${ }^{(2-4,51-53)}$ The Fluid Expansion as Supportive Therapy (FEAST) study indicated that, while fluid management is important in paediatric life support, it needs to be judiciously administered. ${ }^{(51,52)}$

The recommended initial resuscitation fluid of choice in infants and children remains as isotonic crystalloids. ${ }^{(54,55)}$ If the patients show signs of inadequate systemic perfusion, they may benefit from a bolus of $20 \mathrm{~mL} / \mathrm{kg}$ of an isotonic crystalloid. After each bolus, the child's clinical status should be reassessed using the ABCDE approach. This is used as a basis to decide if further fluid boluses or other forms of support are required. In some infants and children, early inotropic support may be required. ${ }^{(56,57)}$ Close attention should be given to the patient's conscious state and respiratory effort, as some patients will require intubation and mechanical ventilation.

\section{Recommendation}

Isotonic crystalloids are recommended as initial resuscitation fluid in infants and children with any type of shock. A fluid bolus of $20 \mathrm{~mL} / \mathrm{kg}$ is used to treat circulatory failure due to hypovolaemia. It is not recommended to give fluid bolus in severe febrile illness when circulatory failure is absent in a child. There should be regular and frequent assessments and reassessments of the child.

\section{Shockable rhythms in paediatric cardiac arrest: VF and pVT defibrillation}

VF and pVT may occur in $7 \%-25 \%$ of children with IHCA, ${ }^{(58)}$ and must be immediately treated with defibrillation and good 
quality CPR. Although it is well accepted that early defibrillation is effective in VF/pVT, the optimal energy dose for safe and effective defibrillation remains to be determined. The evidence available with which to guide defibrillation in children is limited and comes from animal studies, extrapolations from adult data, and historical and recent clinical data. In the 2015 guidelines, the ERC recommends $4 \mathrm{~J} / \mathrm{kg}$, while the AHA recommends $2 \mathrm{~J} / \mathrm{kg}$ for the first shock and $4 \mathrm{~J} / \mathrm{kg}$ for subsequent shocks. ${ }^{(59-62)}$

\section{(a) Energy dose}

Two small case series demonstrated termination of VF/pVT with either $2 \mathrm{~J} / \mathrm{kg}$ or 2-4 J/kg. In an observational study on IHCA, Meaney et $\mathrm{al}^{(63)}$ reported that a higher initial energy dose of $>3-5 \mathrm{~J} / \mathrm{kg}$ was less effective than a dose of $1-3 \mathrm{~J} / \mathrm{kg}$ in achieving ROSC. In a study reporting out-of-hospital paediatric $V F$, Rossano et al $^{(64)}$ found that such patients often received doses that exceeded the recommended, with no survival to discharge advantage compared with patients who received 2-4 J/kg for initial defibrillation. One observational study of $\mathrm{IHCA}^{(58)}$ showed no benefit in achieving ROSC with a specific energy dose for initial defibrillation, but there was a trend of better survival to hospital discharge with a higher mean energy dose per shock (25\% with $<2 \mathrm{~J} / \mathrm{kg}, 43.4 \%$ with $2-4 \mathrm{~J} / \mathrm{kg}$ and $50 \%$ with $>4 \mathrm{~J} / \mathrm{kg}$ ).

\section{Recommendation}

It is reasonable to use an initial and subsequent dose of $4 \mathrm{~J} / \mathrm{kg}$ of monophasic or biphasic energy for defibrillation (Class Ila, LOE C-LD). For refractory $V F$, it is reasonable to consider using higher energy levels, not exceeding $10 \mathrm{~J} / \mathrm{kg}$ or the adult maximum dose (Class IIb, LOE C-LD).

\section{(b) Medications}

The 2005 and 2010 guidelines recommended administering amiodarone in preference to lignocaine for the management of refractory VF or pVT. This recommendation was based predominantly on a paediatric case series ${ }^{(65)}$ and extrapolation from adult studies that used short-term outcomes. ${ }^{(66)}$ Valdes et al ${ }^{(67)}$ recently reported that, in their observational cohort study, the use of lignocaine was associated with an increased likelihood of ROSC, as compared with the use of amiodarone or without the use of lignocaine. However, the same study did not show an association between lignocaine or amiodarone use and survival to hospital discharge.

\section{Recommendation}

The workgroup has revised the sequence of administering medication from what was recommended in 2011. We recommend that adrenaline be given after the second shock; thereafter, this is alternated with either amiodarone or lignocaine (see algorithm for shockable rhythm in Annex A4).

For shock-refractory VF or pVT, either amiodarone or lignocaine may be used. Amiodarone ( $5 \mathrm{mg} / \mathrm{kg}$; maximum dose of $300 \mathrm{mg}$ ) can be administered intravenously or intraosseously

\section{Box 6. Summary of advanced paediatric life support} measures: ${ }^{(8)}$

CPR quality

- Push hard ( $\geq 1 / 3$ of the anteroposterior diameter of the chest) and fast, and allow complete chest recoil; minimise interruptions in compressions.

- For layperson and single rescuer healthcare providers: 30:2 compressions to ventilations

- For team resuscitation in patients with no advanced airway (i.e. supraglottic devices like laryngeal mask airway [LMA]): 15:2 - For team resuscitation with advanced airway (i.e. supraglottic devices like LMA): 100-120 chest compressions per minute with 10 interposed ventilations per minute

\section{Correct reversible causes (Hs \& Ts)}

- Hs: hypovolaemia; hypoxia; hydrogen ion (acidosis); hypoglycaemia; hypo-/hyperkalemia; hypothermia

- Ts: tension pneumothorax; tamponade, cardiac; toxins; thrombosis, pulmonary

\section{Advanced and definitive airway}

- Advanced airway devices include supraglottic airway devices like LMA and endotracheal intubation, while definitive airway refers more specifically to endotracheal intubation (where there is better ventilation and less risk of aspiration).

- Once advanced airway is in place, ventilation is at 10 breaths per min with continuous chest compressions at 100 compressions per minute.

- Waveform capnography or capnometry should be used to confirm and monitor endotracheal tube placement.

\section{Shock energy for defibrillation}

- Defibrillation dose for first and subsequent shock: $4 \mathrm{~J} / \mathrm{kg}$ (maximum $10 \mathrm{~J} / \mathrm{kg}$ or adult dose)

\section{Drug therapy}

- Adrenaline IO/IV dose: $0.01 \mathrm{mg} / \mathrm{kg}(0.1 \mathrm{~mL} / \mathrm{kg}$ of $1: 10,000$ concentration); repeat every 3-5 minutes. If no IO/IV access, may give endotracheal dose: $0.1 \mathrm{mg} / \mathrm{kg}(0.1 \mathrm{~mL} / \mathrm{kg}$ of $1: 1,000$ concentration)

- Amiodarone IO/IV dose: $5 \mathrm{mg} / \mathrm{kg}$ bolus during cardiac arrest; may repeat up to 2 times for refractory VF/pulseless VT

- Lignocaine IO/IV dose: initial: $1 \mathrm{mg} / \mathrm{kg}$ loading dose; maintenance: $20-50 \mathrm{mcg} / \mathrm{kg} / \mathrm{min}$ infusion (repeat bolus dose if infusion initiated > $15 \mathrm{~min}$ after initial bolus therapy)

\section{Return of spontaneous circulation}

- Pulse and blood pressure and/or

- Spontaneous arterial pressure waves with intra-arterial monitoring

in refractory VF or pVT at the third shock and at every alternate shock (up to a maximum of three doses). Lignocaine may be considered an alternative to amiodarone in refractory VF. If lignocaine is used, an initial bolus of $1 \mathrm{mg} / \mathrm{kg}$ (maximum dose of $100 \mathrm{mg}$ ) may be given at the third or fifth shock, followed by a maintenance infusion of $20-50 \mathrm{mcg} / \mathrm{kg} / \mathrm{min}$. If there is a delay between the initial bolus and the start of infusion by more than 15 minutes, another bolus of $1 \mathrm{mg} / \mathrm{kg}$ can be given. Clinicians should choose the drug that they are familiar with, for which they have knowledge of both the expected and unexpected side effects. Box 6 summarises the advanced paediatric life support measures. 


\section{ECMO in CPR and paediatric IHCA}

The workgroup reviewed the current evidence on the effectiveness of extracorporeal membrane oxygenation (ECMO), also known as extracorporeal cardiopulmonary resuscitation (ECPR) in resuscitation, as compared to conventional CPR alone without the use of ECMO. This is a new area of discussion in the 2015 NRC guidelines that was not addressed in the 2011 guidelines.

The 2010 AHA Pediatric Advanced Life Support (PALS) guidelines suggested that ECPR be considered when dealing with paediatric cardiac arrest refractory to conventional interventions and when the underlying disease process is deemed to be reversible in nature. ${ }^{(60)}$ The 2015 ILCOR systematic review looked at the clinically significant outcomes of survival at 180 days with favourable neurological outcome and survival to hospital discharge. ${ }^{(2-4)}$ Paediatric OHCA was not considered in the 2015 ILCOR systematic review. Current evidence on paediatric ECPR is limited to observational studies and retrospective database reviews. Evidence from cardiac arrest registries ${ }^{(68)}$ and the Extracorporeal Life Support Organisation registry(69) suggests that ECMO can be safely and effectively used in paediatric resuscitation.

To date, there is no controlled paediatric trial comparing ECPR and CPR alone, although unmatched observational series and a propensity-matched analysis of a paediatric inpatient database did not show any overall benefit of ECPR compared to $\mathrm{CPR}$ alone in IHCA. ${ }^{(70-73)} \mathrm{ECMO}$, however, was associated with increased complications (e.g. haemorrhage, thrombotic events) and was more resource-intensive. ${ }^{(70)}$ In a retrospective review of a paediatric IHCA registry database, ECPR was shown to improve survival in patients with isolated cardiac disease when CPR alone had failed, especially in surgical cardiac patients. ${ }^{68,70}$ The majority of survivors who received ECPR had a favourable neurological outcome. ${ }^{(68,69)}$ In most series, post-arrest ECPR or ECMO were initiated in cardiac patients. ${ }^{(68,71,72,74)}$ When ECPR was initiated in a critical care setting, long-term survival was also reported in children with underlying cardiac disease even after prolonged conventional CPR. ${ }^{(68)}$

\section{Recommendation}

Given current evidence, the NRC workgroup recommends that for paediatric patients with underlying cardiac disease who have IHCA, ECPR may be considered only in settings with the expertise, resources and systems to optimise the use of ECMO during and after resuscitation.

\section{Intra-arrest prognostic factors}

For both IHCA and OHCA, the use of predictors of positive patient outcome, such as patient age $<1$ year and the initial presence of a shockable rhythm (VF/pVT), should be used to assist prognostic decisions. ${ }^{(40,72,75-85)}$ The taskforce states in the section on the knowledge gap of intra-arrest prognostic factors: ${ }^{(1-3)}$ "Large prospective studies of the association of paediatric cardiac arrest risk factors with outcomes are needed for rescuers to accurately predict successful outcomes and, in particular, to guide decisions on termination of resuscitation." It also adds: "Studies need to be performed that maintain similar resuscitation protocols to reduce the risk of bias from changing treatment strategies, including post-ROSC care."

\section{Recommendation}

We recommend that predictors of positive patient outcomes, such as patient age $<1$ year and the initial presence of a shockable rhythm, should be used to assist in making the prognostic decision during cardiac arrest resuscitation.

\section{Role of ETCO $\mathrm{C}_{2}$ and invasive blood pressure monitoring}

There is a paucity of scientific evidence regarding $\mathrm{ETCO}_{2}$ monitoring and the role of invasive blood pressure monitoring in advanced paediatric life support. ${ }^{(86,87)}$ For the role of $\mathrm{ETCO}_{2}$ monitoring, the taskforce ${ }^{(2-4)}$ found that "the use of capnography during paediatric cardiac arrest has until now been informed by only animal data and extrapolation from adult observational data". For invasive blood pressure monitoring, there were only paediatric animal studies to infer from; these showed the benefit of invasive blood pressure monitoring on critical outcomes such as likelihood of survival to discharge, and ROSC.

\section{Recommendation}

It is reasonable to use $\mathrm{ETCO}_{2}$ and invasive blood pressure monitoring during cardiac arrest, when available, to guide and optimise resuscitative efforts during paediatric cardiac arrest.

\section{Use of vasopressors during arrest}

During arrest, vasopressors can restore spontaneous circulation by improving coronary blood flow and help maintain cerebral perfusion. Conversely, the use of vasopressors can also result in vasoconstriction and increased myocardial oxygen consumption. However, whether its use during arrest actually confers short- or long-term benefits is debatable. Jacobs et al ${ }^{(88)}$ showed improved short-term benefits in adult OHCA patients with the use of adrenaline, in terms of survival to hospital admission and ROSC, but not for longer-term patient outcomes.

Two paediatric out-of-hospital observational studies ${ }^{(89,90)}$ involving 74 patients suggest that the use of vasopressors does not confer certain benefit as compared with non-use of vasopressors in terms of survival with good neurological outcome (Dieckmann et al: RR 2.0; 95\% Cl 0.50-7.98), as well as survival to hospital discharge and ROSC (Dieckmann et al: RR 1.67; 95\% Cl 0.823.41 and RR 0.95; 95\% Cl 0.80-1.14, respectively).

\section{Recommendation}

It is reasonable to use standard-dose adrenaline for paediatric cardiac arrest management.

\section{POST-ARREST PAEDIATRIC ACUTE CARE Post-cardiac arrest targeted temperature management}

The workgroup reviewed evidence for the role of targeted temperature management (TTM) after paediatric cardiac arrest. Data suggests that post-arrest hyperthermia is common in children and associated with poor outcomes. ${ }^{(91)}$ 
The 2010 AHA PALS recommendations for targeted temperature control were largely based on extrapolation of adult and neonatal data. In a recent multicentre, prospective trial involving 260 children (aged two days to 18 years) who remained unconscious after OHCA, the children were randomly assigned to either therapeutic hypothermia (target temperature $33.0^{\circ} \mathrm{C}$ ) or therapeutic normothermia (target temperature $36.8^{\circ} \mathrm{C}$ ) within six hours after return of circulation. The primary efficacy outcome was survival at 12 months after cardiac arrest with neurobehavioural scores of $\geq 70$ on the Vineland Adaptive Behaviour Scales (VAB-II). TTM was maintained for 120 hours in each group, and those assigned to the therapeutic hypothermia arm were pharmacologically paralysed and targeted temperature of $33.0^{\circ} \mathrm{C}$ was maintained for 48 hours before slow rewarming over at least 16 hours, to a targeted temperature of $36.8^{\circ} \mathrm{C}$. This study found no difference in survival, with good functional outcomes at one year and no complications (e.g. infections, bleeding, serious arrhythmias) in patients treated with therapeutic hypothermia $\left(32.0^{\circ} \mathrm{C}-34.0^{\circ} \mathrm{C}\right)$ compared to those treated with normothermia $\left(36.0^{\circ} \mathrm{C}-37.5^{\circ} \mathrm{C}\right)(27 / 138$ versus $15 / 122$; RR $1.54 ; 95 \% \mathrm{Cl}$ $0.85-2.76)^{(92)}$ (moderate quality evidence, downgraded for imprecision).

Observational data from paediatric patients resuscitated from IHCA or OHCA has shown that ICU duration of stay, neurological outcomes and mortality are unchanged with the use of therapeutic hypothermia ${ }^{(93,94)}$ (very low quality evidence, downgraded for bias and imprecision), and therapeutic hypothermia has been associated with the risk of bradycardia and hypotension. ${ }^{(95)}$ Only a small retrospective study of therapeutic hypothermia in survivors of paediatric asphyxia arrest (IHCA and OHCA) showed improvement in mortality at hospital discharge, albeit with no difference in neurological outcomes $^{(96)}$ (very low quality evidence, downgraded for risk of bias and imprecision).

For infants and children successfully resuscitated after IHCA or OHCA, the NRC recommends that TTM be used in the postcardiac arrest period, and that fever (temperature $\geq 38^{\circ} \mathrm{C}$ ) be aggressively treated after ROSC (Class I). Based on the available data, ${ }^{(2-4)}$ it is reasonable to use either five days of normothermia $\left(36^{\circ} \mathrm{C}-37.5^{\circ} \mathrm{C}\right)$, or two days of hypothermia $\left(32^{\circ} \mathrm{C}-34^{\circ} \mathrm{C}\right)$, followed by three days of normothermia, in children who remain comatose after OHCA. However, given the paucity of evidence for the role of, and in view of the potential risks associated with, therapeutic hypothermia, the NRC workgroup recommends that normothermia $\left(36^{\circ} \mathrm{C}-37.5^{\circ} \mathrm{C}\right)$ be maintained in children who remain comatose after OHCA. In light of the insufficient evidence to recommend cooling over normothermia in children who remain comatose after IHCA, the workgroup recommends maintenance of normothermia $\left(36^{\circ} \mathrm{C}-37.5^{\circ} \mathrm{C}\right)$.

\section{Recommendation}

We recommend that normothermia $\left(36^{\circ} \mathrm{C}-37.5^{\circ} \mathrm{C}\right)$ be maintained in children who remain comatose after $\mathrm{OHCA}$ or IHCA.

\section{Post-ROSC ventilation and $\mathrm{PO}_{2} / \mathrm{PCO}_{2} /$ post-ROSC fluids and inotropes}

There are very few studies looking at optimal ventilation strategies post-ROSC in children.

\section{(a) Post-ROSC $\mathrm{PO}_{2}$ targets}

Four observational studies ${ }^{(97-100)}$ evaluated post-ROSC normoxaemia or hyperoxaemia in children for the following: survival to hospital discharge with good neurological outcome (Bennett: RR 1.27; 95\% Cl 0.86-1.90); survival to six months (Guerra-Wallace: RR $1.09 ; 95 \% \mathrm{Cl} 0.81-1.46$ ); survival to hospital discharge (Del Castillo: RR 1.25; 95\% Cl 0.76-2.05); and survival to paediatric ICU discharge (Ferguson: RR 1.08; 95\% Cl 0.95-1.23).

\section{Recommendation}

In children with ROSC, we recommend supporting ventilation and aiming to achieve 12 breaths per minute ( $>8$ years old) and 20 breaths per minute (1-8 years old). It is reasonable to measure $\mathrm{PaO}_{2}$ after ROSC, and to target a value appropriate to the specific patient condition and state. In the absence of specific patient data and condition, it is reasonable to target normoxaemia after ROSC. It is also reasonable to use pulse oximetry after ROSC and aim for an oxygen saturation range of $94 \%-98 \%$.

\section{(b) Post-ROSC $\mathrm{PCO}_{2}$ targets}

One paediatric observational study of IHCA and OHCA involved 195 survivors who were observed for at least six hours after arrest. The outcome measured was survival to hospital discharge with favourable/functional neurological outcome (assessed with paediatric cerebral performance category [PCPC 1-2] or no change from baseline before cardiac arrest). ${ }^{(97)}$ Bennett et al found no association between hypercapnia $\left(\mathrm{PaCO}_{2}>50 \mathrm{~mm} \mathrm{Hg}\right)$ and outcome (RR 0.76; 95\% Cl 0.50-1.16). ${ }^{(97)}$ Conversely, Del Castillo et al's paediatric observational study ${ }^{(99)}$ of IHCA involving 223 subjects showed that worse outcomes (survival to hospital discharge) were associated with hypercapnia $\left(\mathrm{PaCO}_{2}\right.$ $\geq 50 \mathrm{mmHg}$ ) than with $\mathrm{PaCO}_{2}<50 \mathrm{mmHg}(\mathrm{RR} 0.48 ; 95 \% \mathrm{Cl}$ $0.27-0.86)$.

Both the observational studies of Bennett et al and Del Castillo et al did not show any association between hypocapnia and outcome (survival to hospital discharge with favourable/ functional neurological outcome (assessed with PCPC 1-2 or no change with baseline before cardiac arrest, and survival to hospital discharge, respectively - RR 0.70; 95\% Cl 0.43-1.14

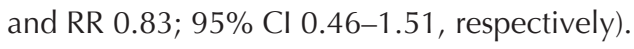

\section{Recommendation}

It is reasonable to measure $\mathrm{PaCO}_{2}$ after ROSC and to target a value appropriate to the specific patient condition and state. We suggest that normocapnia is a reasonable target during resuscitation, as both hypo- and hypercapnia have adverse consequences, which are not desirable. 


\section{(c) Post-ROSC fluid and inotrope therapy}

The issue of optimal post-ROSC fluid and inotrope regime in paediatric patients has only been addressed in observational studies. Topjian et $\mathrm{al}^{(101)}$ conducted a paediatric observational study of IHCA and OHCA in 367 children. Patients with systolic blood pressure lower than the fifth percentile for age after ROSC showed worse outcomes, i.e. survival to hospital discharge with good neurological outcome (RR 0.78; 95\% Cl 0.62-0.99). Two other paediatric observational studies ${ }^{(102,103)}$ of IHCA and OHCA involving a total of 615 children showed worse outcomes (survival to hospital discharge) in patients who experienced hypotension after ROSC. There was significant heterogeneity (I-squared value 0.87 ), which does not support pooling of data from the aforementioned studies (Topjian: OR 0.62; 95\% Cl 0.41-0.93; Lin: OR $0.10 ; 95 \% \mathrm{Cl} 0.03-0.32$; and Lin: OR $0.07 ; 95 \% \mathrm{Cl}$ 0.02-0.25).

\section{Recommendation}

Post-ROSC, it is reasonable to maintain normal blood pressure that is appropriate for the age of the child through the use of parenteral fluids and/or inotropes or vasopressors. The minimum paediatric systolic blood pressure according to age is as follows: $:^{(104-106)}$

- $\quad$ Term neonates (0-28 days) - $60 \mathrm{mmHg}$

- Infants (1-12 mth) - $70 \mathrm{mmHg}$

- $\quad$ Children (1-10 yr) [5th BP percentile] - $70+($ age in $y r \times 2)$

- $\quad$ Children $>10 \mathrm{yr}-90 \mathrm{mmHg}$

\section{Post-ROSC predictive factors}

\section{(a) Post-ROSC EEG}

Two paediatric observational studies ${ }^{(107,108)}$ involving a total of 68 patients showed that an electroencephalogram (EEG) (performed within the first seven days after cardiac arrest) that demonstrates a continuous and reactive tracing was associated with a higher likelihood of good neurological outcome at hospital discharge (RR 4.18; 95\% Cl 2.25-7.75). In comparison, patients with an EEG demonstrating a discontinuous or isoelectric tracing had a higher likelihood of poor neurological outcome at hospital discharge (RR 2.19; 95\% Cl 1.51-3.77).

\section{Recommendation}

It is reasonable to consider the use of an EEG within the first seven days after cardiac arrest to assist in prognostication.

\section{(b) Other post-ROSC predictive factors}

The presence of a positive pupillary light reflex post-ROSC suggests good predictive outcomes: from survival up to 180 days with good neurological outcome to survival to hospital discharge with good neurological outcomes. ${ }^{(109)}$ Other observational studies show better outcomes when post-ROSC levels of lactate and neuron-specific enolase or S100B serum levels are lower. ${ }^{(110-112)}$

\section{Recommendation}

It is reasonable to use multiple variables, such as reactivity of pupils and serum markers after cardiac arrest, to predict outcomes for infants and children after cardiac arrest.

\section{Paediatric post-arrest checklist}

The workgroup reviewed the AHA post-arrest checklist ${ }^{(8)}$ and came up with a post-arrest checklist for paediatric resuscitation (Box 7).

\section{Box 7. Paediatric post-arrest checklist: \\ A\&B: oxygenation and ventilation}

- $\mathrm{O}_{2}$ : Avoid hypoxia; measure oxygenation and target

normoxaemia (maintain $\mathrm{SpO}_{2}$ at 94\%-98\%)

- $\mathrm{CO}_{2}$ : Measure $\mathrm{PaCO}_{2}$, and target a clinically appropriate value and avoid hypocapnia

\section{Circulation: haemodynamic monitoring}

- Set haemodynamic goals post-return of spontaneous circulation and monitor blood pressure

- Use parenteral fluids and/or inotropes or vasopressors to maintain a systolic blood pressure greater than the 5 th percentile.

\section{Disability: neuromonitoring}

- Treat clinical seizures and do not routinely use pharmacologic prophylaxis for seizures

\section{Environment and exposure: targeted temperature}

\section{management (TTM)}

- Measure and monitor core temperature; prevent and treat fever

- Normothermia $\left(36^{\circ} \mathrm{C}-37.5^{\circ} \mathrm{C}\right)$ should be maintained in children who remain comatose after out-of-hospital and in-hospital cardiac arrest

\section{Glucose control}

- Measure glucose and avoid hypoglycaemia (keep blood glucose above $3.0-3.5 \mathrm{mmol} / \mathrm{L}$ )

\section{Prognosis}

- Always consider multiple modalities (clinical and others) over any single predictor factor

- Electroencephalogram may be useful within the first seven days and somatosensory evoked potentials may be useful after 72 hours

- Blood biomarkers may be measured repeatedly over 72 hours

- Neuroimaging such as computed tomography in the initial hours and magnetic resonance imaging during the first six days may be of value.

- Remember that assessments may be modified by TTM or induced hypothermia.

\section{CONCLUSION}

Many of the paediatric recommendations from ILCOR, AHA and ERC have thus far been extrapolated from adult studies and animal models. There currently exists a limited amount of objective scientific paediatric resuscitation evidence. Therefore, more consolidated research needs to be done for paediatric resuscitation. The use of resuscitation registries to capture resuscitation data and concurrent use of feedback devices will help further fine-tune and improve paediatric resuscitation science and practice. For example, the creation of a national and regional paediatric resuscitation registry will help determine the prognostic factors for post-ROSC survival outcomes. 


\section{SUMMARY OF RECOMMENDATIONS}
(A) PRE-ARREST PAEDIATRIC ACUTE CARE
Paediatric Early Warning
Score (PEWS) and medical emergency team (MET)/rapid
response team (RRT)
- It is reasonable to use PEWS in the in-hospital setting and MET/RRT systems in facilities where children with high-risk illnesses are cared for in general inpatient units. (Class IIb, $L O E C-L D)$
- It appears rational that intervening earlier in the course of development of a medical emergency provides greater scope for limiting the harmful effects of the condition and promoting recovery.
- The decision to use a MET/RRT system should be balanced by the existing resources and capabilities of the institution.
- Training of emergency response teams needs to be addressed so that evidence-based interventions can be brought into play to truncate the deterioration that is picked up by the early warning systems.
- Simulation-based MET training exercises have been linked to improved team performance and outcome.

\section{(B) BASIC PAEDIATRIC LIFE SUPPORT}

Recognition and assessment of cardiac arrest and initial management of collapse

\section{Compression-ventilation ratio}

\section{Chest compression depth}

Chest compression-only CPR

\section{Foreign body airway} obstruction (FBAO)

\section{Use of automated external} defibrillators (AEDs) in paediatric cardiac arrest
- We recommend to first open the airway patency and check for breathing and, if absent, to start chest compressions for children.

- One should take not more than ten seconds to determine if there is cardiac arrest.

- The presence or absence of a pulse is not a reliable determinant of cardiac arrest.

- Other determinants of cardiac arrest are unresponsiveness, gasping and not breathing normally, and no signs of life.

- For layperson and single rescuer healthcare providers, we recommend a compression-ventilation ratio of 30:2 for children.

- For healthcare providers with more than one rescuer, we recommend 15:2 in the absence of advanced airway devices (i.e. supraglottic devices like laryngeal mask airway [LMA] or endotracheal intubation), and continuous chest compressions at 100-120/min with interposed ventilations at $10 / \mathrm{min}$ for children with advanced airway devices.

- We recommend that the chest compression depth for paediatric cardiopulmonary resuscitation (CPR) be at least one-third the anteroposterior diameter for infants and children, or about $4 \mathrm{~cm}$ and $5 \mathrm{~cm}$, respectively.

- We recommend against routine chest compression-only CPR for children. However, rescuers who are unable or unwilling to provide mouth-to-mouth ventilation are encouraged to perform at least good quality chest compressions.

- Infants should have chest thrusts to help dislodge the foreign body.

- Abdominal thrusts (Heimlich manoeuvre) are not recommended for infants.

- Children aged $\geq 1$ year may be given abdominal thrusts (Heimlich manoeuvre) for FBAO care.

- Paediatric dose-attenuating systems can be used in children aged 1-8 years to reduce the energy dose delivered by the AED. This may be done either via a paediatric-specific (attenuated) pad-cable system, or an AED with a paediatric mode or switch to select for half of the adult energy dose. Most paediatric-specific attenuation pads deliver 50-75 J.

\section{C) ADVANCED PAEDIATRIC LIFE SUPPORT}

LMA and supraglottic devices

Use of atropine for premedication in emergency intubation

\section{Fluid management}

- When ventilation is difficult and/or endotracheal intubation is not possible during paediatric resuscitation, appropriate supraglottic airway devices, especially LMA, if available, is recommended when used by experienced providers to provide a patent airway and support ventilation.

- Atropine $(0.02 \mathrm{mg} / \mathrm{kg})$ may be used as premedication in emergency intubations where there is a risk of bradycardia, e.g. succinylcholine is used to facilitate intubation.

- There is no absolute minimum dose of atropine and its dosage should be guided by the weight of the patient.

- Isotonic crystalloids are recommended as initial resuscitation fluid in infants and children with any type of shock.

- A fluid bolus of $20 \mathrm{~mL} / \mathrm{kg}$ is used to treat circulatory failure due to hypovolaemia.

- It is not recommended to give fluid bolus in severe febrile illness when circulatory failure is absent in a child.

- There should be regular and frequent assessments and reassessments of the child. 


\section{SUMMARY OF RECOMMENDATIONS (Continued)}

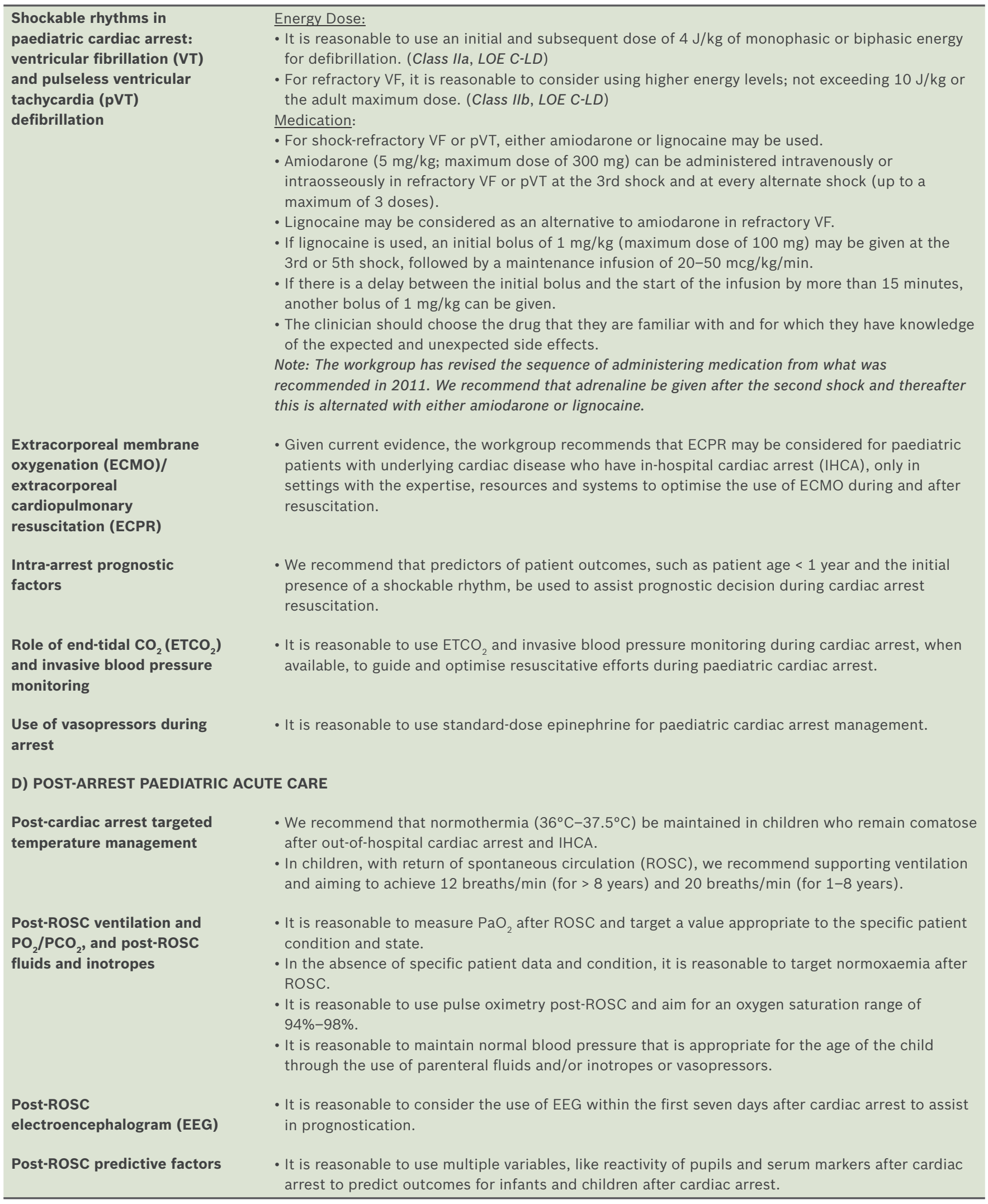

\section{ACKNOWLEDGEMENTS}

The authors would like to thank Prof $V$ Anantharaman, Chairman of the National Resuscitation Council, and A/Prof Lim Swee Han,
Immediate Past President of the Resuscitation Council of Asia, for their invaluable input during the workgroup discussions and in the preparation of this set of recommendations. 


\section{REFERENCES}

1. Singapore National Resuscitation Council's Neonatal and Paediatric Resuscitation Workgroup, Chong NK. Newborn and paediatric resuscitation 2011 guidelines. Singapore Med J 2011; 52:560-72.

2. de Caen AR, Maconochie IK, Aickin R, et al; Pediatric Basic Life Support and Pediatric Advanced Life Support Chapter Collaborators. Part 6: Pediatric Basic Life Support and Pediatric Advanced Life Support: 2015 International Consensus on Cardiopulmonary Resuscitation and Emergency Cardiovascula Care Science with Treatment Recommendations. Circulation 2015; 132(16 Suppl 1):S177-203.

3. Maconochie IK, de Caen AR, Aickin R, et al; Pediatric Basic Life Support and Pediatric Advanced Life Support Chapter Collaborators. Part 6: Pediatric basic life support and pediatric advanced life support: 2015 International Consensus on Cardiopulmonary Resuscitation and Emergency Cardiovascular Care Science with Treatment Recommendations. Resuscitation 2015 95:e147-68.

4. de Caen AR, Maconochie IK, Aickin R, et al; Pediatric Basic Life Support Pediatric Advanced Life Support Chapter Collaborators. Part 6: Pediatric Basic Life Support and Pediatric Advanced Life Support: 2015 Internationa Consensus on Cardiopulmonary Resuscitation and Emergency Cardiovascula Care Science With Treatment Recommendations (Reprint). Pediatrics 2015; 136 Suppl 2:S88-119.

5. Schünemann H, Brozek J, Guyatt G, Oxman A. GRADE handbook for grading quality of evidence and strength of recommendations. 2013 [online]. Available at: http://guidelinedevelopment.org/handbook. Accessed March 27, 2017.

6. Evidence Prime Inc. GRADEpro Guideline Development Tool. Available at: http://www.guidelinedevelopment.org/. Accessed March 27, 2017.

7. Atkins DL, Berger S, Duff JP, et al. Part 11: Pediatric Basic Life Support and Cardiopulmonary Resuscitation Quality: 2015 American Heart Association Guidelines Update for Cardiopulmonary Resuscitation and Emergency Cardiovascular Care. Circulation 2015; 132(18 Suppl 2):S519-25.

8. de Caen AR, Berg MD, Chameides L, et al. Part 12: Pediatric Advanced Life Support: 2015 American Heart Association Guidelines Update for Cardiopulmonary Resuscitation and Emergency Cardiovascular Care. Circulation 2015; 132(18 Suppl 2):S526-42

9. Maconochie IK, Bingham R, Eich C; Paediatric life support section Collaborators. European Resuscitation Council Guidelines for Resuscitation 2015: Section 6. Paediatric life support. Resuscitation 2015; 95:223-48.

10. European Resuscitation Council. Summary of the main changes in the Resuscitation Guidelines. ERC Guidelines 2015. Available at: https://cprguidelines.eu/ sites/573c777f5e61585a053d7ba5/assets/573c77d75e61585a083d7ba8/ ERC summary booklet_HRES.pdf. Accessed March 27, 2017.

11. Pearson G, Duncan H. Early warning systems for identifying sick children Paediatr Child Health 2011; 21:230-3.

12. Randhawa S, Roberts-Turner R, Woronick K, DuVal J. Implementing and sustaining evidence-based nursing practice to reduce pediatric cardiopulmonary arrest. West J Nurs Res 2011; 33:443-56.

13. Kotsakis A, Lobos AT, Parshuram C, et al; Ontario Pediatric Critical Care Response Team Collaborative. Implementation of a multicenter rapid response system in pediatric academic hospitals is effective. Pediatrics $2011 ; 128: 72-8$

14. Tibballs J, Kinney S. Reduction of hospital mortality and preventable cardiac arrest and death on introduction of a pediatric medical emergency team. Pediatr Crit Care Med 2009; 10:306-12.

15. Knight LJ, Gabhart JM, Earnest KS, et al. Improving code team performance and survival outcomes: implementation of pediatric resuscitation team training. Crit Care Med 2014; 42:243-51.

16. Bonafide $\mathrm{CP}$, Localio $\mathrm{AR}$, Roberts $\mathrm{KE}$, et al. Impact of rapid response system implementation on critical deterioration events in children. JAMA Pediat 2014; 168:25-33

17. Joffe AR, Anton NR, Burkholder SC. Reduction in hospital mortality ove time in a hospital without a pediatric medical emergency team: limitations of before-and-after study designs. Arch Pediatr Adolesc Med 2011; 165:419-23.

18. Bonafide CP, Roberts KE, Priestley MA, et al. Development of a pragmatic measure for evaluating and optimizing rapid response systems. Pediatrics 2012; 129:e874-81.

19. Lubrano R, Cecchetti C, Bellelli E, et al. Comparison of times of intervention during pediatric $C P R$ maneuvers using $A B C$ and $C A B$ sequences: a randomized trial. Resuscitation 2012; 83:1473-7.

20. Marsch S, Tschan F, Semmer NK, et al. ABC versus CAB for cardiopulmonary resuscitation: a prospective, randomized simulator-based trial. Swiss Med Wkly 2013; 143:w13856.

21. Sekiguchi H, Kondo Y, Kukita I. Verification of changes in the time taken to initiate chest compressions according to modified basic life support guidelines. Am J Emerg Med 2013; 31:1248-50.

22. McDonald $\mathrm{CH}$, Heggie J, Jones $\mathrm{CM}$, Thorne $\mathrm{C}$ J, Hulme J. Rescuer fatigue under the 2010 ERC guidelines, and its effect on cardiopulmonary resuscitation (CPR) performance. Emerg Med J 2013; 30:623-7.

23. Heidenreich JW, Berg RA, Higdon TA, et al. Rescuer fatigue: standard versus continuous chest-compression cardiopulmonary resuscitation. Acad Emerg Med 2006; 13:1020-6.

24. Sutton RM, French B, Niles DE, et al. 2010 American Heart Association recommended compression depths during pediatric in-hospital resuscitations are associated with survival. Resuscitation 2014; 85:1179-84

25. Sutton RM, Wolfe $H$, Nishisaki $A$, et al. Pushing harder, pushing faster, minimizing interruptions... but falling short of 2010 cardiopulmonary resuscitation targets during in-hospital pediatric and adolescent resuscitation. Resuscitation 2013; 84:1680-4.

26. Maher KO, Berg RA, Lindsey CW, Simsic J, Mahle WT. Depth of sternal compression and intra-arterial blood pressure during CPR in infants following cardiac surgery. Resuscitation 2009; 80:662-4.

27. Kitamura $\mathrm{T}$, Iwami $\mathrm{T}$, Kawamura $\mathrm{T}$, et al; implementation working group for All-Japan Utstein Registry of the Fire and Disaster Management Agency. Conventional and chest-compression-only cardiopulmonary resuscitation by bystanders for children who have out-of-hospital cardiac arrests: a prospective, nationwide, population-based cohort study. Lancet 2010; 375:1347-54.

28. Goto Y, Maeda T, Goto Y. Impact of dispatcher-assisted bystander cardiopulmonary resuscitation on neurological outcomes in children with out-of-hospital cardiac arrests: a prospective, nationwide, population-based cohort study. J Am Heart Assoc 2014; 3:e000499.

29. International Liaison Committee on Resuscitation. 2005 International Consensus on Cardiopulmonary Resuscitation and Emergency Cardiovascular Care Science with Treatment Recommendations. Part 6: Paediatric basic and advanced life support. Resuscitation 2005; 67:271-91.

30. Kleinman ME, Chameides L, Schexnayder SM, et al. Part 14: pediatric advanced life support: 2010 American Heart Association Guidelines for Cardiopulmonary Resuscitation and Emergency Cardiovascular Care. Circulation 2010; 122(18 Suppl 3):S876-908.

31. Berg MD, Schexnayder SM, Chameides L, et al. Part 13: pediatric basic life support: 2010 American Heart Association Guidelines for Cardiopulmonary Resuscitation and Emergency Cardiovascular Care. Circulation 2010; 122(18 Suppl 3):S862-75.

32. Atkins DL, Berger S. Improving outcomes from out-of-hospital cardiac arrest in young children and adolescents. Pediatr Cardiol 2012; 33:474-83.

33. Kovach J, Berger S. Automated external defibrillators and secondary prevention of sudden cardiac death among children and adolescents. Pediatr Cardiol 2012; 33:402-6

34. Cecchin $\mathrm{F}$, Jorgenson DB, Berul $\mathrm{Cl}$, et al. Is arrhythmia detection by automatic external defibrillator accurate for children?: sensitivity and specificity of an automatic external defibrillator algorithm in 696 pediatric arrhythmias. Circulation 2001; 103:2483-8.

35. Atkins DL, Scott WA, Blaufox AD, et al. Sensitivity and specificity of an automated external defibrillator algorithm designed for pediatric patients. Resuscitation 2008; 76:168-74.

36. Rossano JW, Jones WE, Lerakis $\mathrm{S}$, et al. The use of automated external defibrillators in infants: a report from the American Red Cross Scientific Advisory Council. Pediatr Emerg Care 2015; 31:526-30.

37. Keil J, Jung $\mathrm{P}$, Schiele A, et al. [Interdisciplinary consensus statement on alternative airway management with supraglottic airway devices in pediatric emergency medicine: Laryngeal mask is state of the art]. Anaesthesist 2016; 65:57-66. German.

38. Patel B, Bingham R. Laryngeal mask airway and other supraglottic airway devices in paediatric practice. Contin Educ Anaesth Crit Care Pain 2009; 9:6-9.

39. Fowler RL, Leba C, Mehkri F, Idris AH. The BVM Effect. An overview of studies assessing airway management in out-of-hospital cardiac arrest. JEMS 2015; 40:58-61, 67.

40. Atkins DL, Everson-Stewart S, Sears GK, et al. Epidemiology and outcomes from out-of-hospital cardiac arrest in children: the Resuscitation Outcomes Consortium Epistry-Cardiac Arrest. Circulation 2009; 119:1484-91.

41. Blevin AE, McDouall SF, Rechner JA, et al. A comparison of the laryngeal mask airway with the facemask and oropharyngeal airway for manual ventilation by first responders in children. Anaesthesia 2009; 64:1312-6.

42. Jagannathan N, Ramsey MA, White MC, Sohn L. An update on newer pediatric supraglottic airways with recommendations for clinical use. Paediatr Anaesth 2015; 25:334-45.

43. Jones P, Peters MJ, Pinto da Costa N, et al. Atropine for critical care intubation in a cohort of 264 children and reduced mortality unrelated to effects on bradycardia. PLoS One 2013; 8:e57478.

44. Jones P, Dauger S, Denjoy I, et al. The effect of atropine on rhythm and conduction disturbances during 322 critical care intubations. Pediatr Crit Care Med 2013; 14:e289-97.

45. Fastle RK, Roback MG. Pediatric rapid sequence intubation: incidence of reflex bradycardia and effects of pretreatment with atropine. Pediatr Emerg Care 2004; 20:651-5.

46. McAuliffe G, Bissonnette B, Boutin C. Should the routine use of atropine before succinylcholine in children be reconsidered? Can J Anaesth 1995; 42:724-9.

47. Fleming B, McCollough M, Henderson HO. Myth: Atropine should be administered before succinylcholine for neonatal and pediatric intubation. 
CJEM 2005; 7:114-7.

48. Eisa L, Passi Y, Lerman J, Raczka M, Heard C. Do small doses of atropine ( $<0.1 \mathrm{mg})$ cause bradycardia in young children? Arch Dis Child 2015; 100:684-8

49. Barrington KJ. The myth of a minimum dose for atropine. Pediatrics 2011 127:783-4.

50. Carcillo JA, Fields Al; Comitê de Força-Tarefa. [Clinical practice parameters for hemodynamic support of pediatric and neonatal patients in septic shock]. J Pediatr (Rio J) 2002; 78:449-66. Portuguese.

51. Maitland K, Kiguli S, Opoka RO, et al; FEAST Trial Group. Mortality after fluid bolus in African children with severe infection. N Engl J Med 2011; 364:2483-95.

52. Maitland K, George EC, Evans JA, et al; FEAST trial group. Exploring mechanisms of excess mortality with early fluid resuscitation: insights from the FEAST trial. BMC Med 2013; 11:68.

53. Kelm DJ, Perrin JT, Cartin-Ceba R, et al. Fluid overload in patients with severe sepsis and septic shock treated with early goal-directed therapy is associated with increased acute need for fluid-related medical interventions and hospital death. Shock 2015; 43:68-73.

54. Perel P, Roberts I, Ker K. Colloids versus crystalloids for fluid resuscitation in critically ill patients. Cochrane Database Syst Rev 2013; 2:CD000567.

55. SAFE Study Investigators; Australian and New Zealand Intensive Care Society Clinical Trials Group; Australian Red Cross Blood Service; George Institute for International Health, Myburgh J, Cooper DJ, et al. Saline or albumin fo fluid resuscitation in patients with traumatic brain injury. N Engl J Med 2007 357:874-84.

56. Levy B, Perez P, Perny J, Thivilier C, Gerard A. Comparison of norepinephrinedobutamine to epinephrine for hemodynamics, lactate metabolism, and organ function variables in cardiogenic shock. A prospective, randomized pilot study. Crit Care Med 2011; 39:450-5

57. Dellinger RP, Levy MM, Rhodes A, et al; Surviving Sepsis Campaign Guidelines Committee including The Pediatric Subgroup. Surviving Sepsis Campaign: international guidelines for management of severe sepsis and septic shock 2012. Intensive Care Med 2013; 39:165-228.

58. Rodríguez-Nuñez A, López-Herce J, del Castillo J, Bellón JM; Iberian-American Paediatric Cardiac Arrest Study Network RIBEPCI. Shockable rhythms and defibrillation during in-hospital pediatric cardiac arrest. Resuscitation 2014 85:387-91

59. Biarent D, Bingham R, Eich C, et al. European Resuscitation Council Guidelines for Resuscitation 2010 Section 6. Pediatric life support. Resuscitation 2010 81:1364-88.

60. Kleinman ME, de Caen AR, Chameides L, et al; Pediatric Basic and Advanced Life Support Chapter Collaborators. Part 10: Pediatric basic and advanced life support: 2010 International Consensus on Cardiopulmonary Resuscitation and Emergency Cardiovascular Care Science With Treatment Recommendations. Circulation 2010; 122(16 Suppl 2):S466-515.

61. Gutgesell HP, Tacker WA, Geddes LA, et al. Energy dose for ventricular defibrillation of children. Pediatrics 1976; 58:898-901

62. Berg MD, Samson RA, Meyer RJ, et al. Paediatric defibrillation doses often fail to terminate prolonged out-of-hospital ventricular fibrillation in children. Resuscitation 2005; 67:63-7.

63. Meaney PA, Nadkarni VM, Atkins DL, et al; American Heart Association National Registry of Cardiopulmonary Resuscitation Investigators. Effect of defibrillation energy dose during in-hospital pediatric cardiac arrest. Pediatrics 2011; 127:e16-23.

64. Rossano JW, Quan L, Kenney MA, Rea TD, Atkins DL. Energy doses for treatment of out-of-hospital pediatric ventricular fibrillation. Resuscitation 2006; 70:80-9

65. Perry JC, Fenrich AL, Hulse JE, et al. Pediatric use of intravenous amiodarone: efficacy and safety in critically ill patients from a multicenter protocol. J Am Coll Cardiol 1996; 27:1246-50.

66. Dorian P, Cass D, Schwartz B, et al. Amiodarone as compared with lidocaine for shock-resistant ventricular fibrillation. N Engl J Med 2002; 346:884-90.

67. Valdes SO, Donoghue AJ, Hoyme DB, et al; American Heart Association Get With The Guidelines-Resuscitation Investigators. Outcomes associated with amiodarone and lidocaine in the treatment of in-hospital pediatric cardiac arrest with pulseless ventricular tachycardia or ventricular fibrillation. Resuscitation 2014; 85:381-6.

68. Raymond TT, Cunnyngham CB, Thompson MT, et al; American Heart Association National Registry of CPR Investigators. Outcomes among neonates, infants, and children after extracorporeal cardiopulmonary resuscitation for refractory inhospital pediatric cardiac arrest: a report from the National Registry of Cardiopulmonary Resuscitation. Pediatr Crit Care Med 2010; 11:362-71.

69. Doski JJ, Butler TJ, Louder DS, Dickey LA, Cheu HW. Outcome of infants requiring cardiopulmonary resuscitation before extracorporeal membrane oxygenation. J Pediatr Surg 1997; 32:1318-21.

70. Lowry AW, Morales DL, Graves DE, et al. Characterization of extracorporea membrane oxygenation for pediatric cardiac arrest in the United States: analysis of the kids' inpatient database. Pediatr Cardiol 2013; 34:1422-30.

71. Wu ET, Li MJ, Huang SC, et al. Survey of outcome of CPR in pediatric in-hospital cardiac arrest in a medical center in Taiwan. Resuscitation 2009; 80:443-8.
72. de Mos N, van Litsenburg RR, McCrindle B, Bohn DJ, Parshuram CS. Pediatric in-intensive-care-unit cardiac arrest: incidence, survival, and predictive factors. Crit Care Med 2006; 34:1209-15.

73. Odegard KC, Bergersen L, Thiagarajan R, et al. The frequency of cardiac arrests in patients with congenital cardiac disease undergoing cardiac catherization. Anesth Analg 2014; 118:175-82.

74. Morris MC, Wernovsky G, Nadkarni VM. Survival outcomes after extracorporeal cardiopulmonary resuscitation instituted during active chest compressions following refractory in-hospital pediatric cardiac arrest. Pediatr Crit Care Med 2004; 5:440-6.

75. Ortmann L, Prodhan P, Gossett J, et al; American Heart Association's Get With The Guidelines-Resuscitation Investigators. Outcomes after in-hospital cardiac arrest in children with cardiac disease: a report from Get With the Guidelines--Resuscitation. Circulation 2011; 124:2329-37.

76. Moler FW, Meert K, Donaldson AE, et al; Pediatric Emergency Care Applied Research Network. In-hospital versus out-of-hospital pediatric cardiac arrest: a multicenter cohort study. Crit Care Med 2009; 37:2259-67.

77. Young KD, Gausche-Hill M, McClung CD, Lewis RJ. A prospective, populationbased study of the epidemiology and outcome of out-of-hospital pediatric cardiopulmonary arrest. Pediatrics 2004; 114:157-64.

78. Moler FW, Donaldson AE, Meert K, et al; Pediatric Emergency Care Applied Research Network. Multicenter cohort study of out-of-hospital pediatric cardiac arrest. Crit Care Med 2011; 39:141-9.

79. López-Herce J, García C, Domínguez P, et al; Spanish Study Group of Cardiopulmonary Arrest in Children. Outcome of out-of-hospital cardiorespiratory arrest in children. Pediatr Emerg Care 2005; 21:807-15.

80. López-Herce J, Del Castillo J, Matamoros M, et al; Iberoamerican Pediatric Cardiac Arrest Study Network RIBEPCI. Factors associated with mortality in pediatric in-hospital cardiac arrest: a prospective multicenter multinational observational study. Intensive Care Med 2013; 39:309-18.

81. Meert KL, Donaldson A, Nadkarni V, et al; Pediatric Emergency Care Applied Research Network. Multicenter cohort study of in-hospital pediatric cardiac arrest. Pediatr Crit Care Med 2009; 10:544-53.

82. Meaney PA, Nadkarni VM, Cook EF, et al; American Heart Association National Registry of Cardiopulmonary Resuscitation Investigators. Higher survival rates among younger patients after pediatric intensive care unit cardiac arrests. Pediatrics 2006; 118:2424-33.

83. Tibballs J, Kinney S. A prospective study of outcome of in-patient paediatric cardiopulmonary arrest. Resuscitation 2006; 71:310-8.

84. Reis AG, Nadkarni V, Perondi MB, Grisi S, Berg RA. A prospective investigation into the epidemiology of in-hospital pediatric cardiopulmonary resuscitation using the international Utstein reporting style. Pediatrics 2002; 109:200-9.

85. Haque A, Rizvi A, Bano S. Outcome of in-hospital pediatric cardiopulmonary arrest from a single center in Pakistan. Indian J Pediatr 2011; 78:1356-60.

86. Sutton RM, Friess $\mathrm{SH}$, Bhalala $U$, et al. Hemodynamic directed $\mathrm{CPR}$ improves short-term survival from asphyxia-associated cardiac arrest. Resuscitation 2013; 84:696-701

87. Friess $\mathrm{SH}$, Sutton RM, Bhalala $U$, et al. Hemodynamic directed cardiopulmonary resuscitation improves short-term survival from ventricular fibrillation cardiac arrest. Crit Care Med 2013; 41:2698-704.

88. Jacobs IG, Finn JC, Jelinek GA, Oxer HF, Thompson PL. Effect of adrenaline on survival in out-of-hospital cardiac arrest: a randomised double-blind placebocontrolled trial. Resuscitation 2011; 82:1138-43.

89. Enright K, Turner C, Roberts P, Cheng N, Browne G. Primary cardiac arrest following sport or exertion in children presenting to an emergency department: chest compressions and early defibrillation can save lives, but is intravenous epinephrine always appropriate? Pediatr Emerg Care 2012; 28:336-9.

90. Dieckmann RA, Vardis R. High-dose epinephrine in pediatric out-of-hospital cardiopulmonary arrest. Pediatrics 1995; 95:901-13.

91. Bembea MM, Nadkarni VM, Diener-West M, et al; American Heart Association National Registry of Cardiopulmonary Resuscitation Investigators. Temperature patterns in the early postresuscitation period after pediatric inhospital cardiac arrest. Pediatr Crit Care Med 2010; 11:723-30.

92. Moler FW, Silverstein FS, Holubkov R, et al; THAPCA Trial Investigators. Therapeutic hypothermia after out-of-hospital cardiac arrest in children. N Engl J Med 2015; 372:1898-908.

93. Fink EL, Clark RS, Kochanek PM, Bell MJ, Watson RS. A tertiary care center's experience with therapeutic hypothermia after pediatric cardiac arrest. Pediatr Crit Care Med 2010; 11:66-74.

94. Doherty DR, Parshuram CS, Gaboury I, et al; Canadian Critical Care Trials Group. Hypothermia therapy after pediatric cardiac arrest. Circulation 2009; 119:1492-500.

95. Scholefield BR, Morris KP, Duncan HP, et al. Evolution, safety and efficacy of targeted temperature management after pediatric cardiac arrest. Resuscitation 2015; 92:19-25

96. Lin J, Hsia SH, Wang HS, Chiang MC, Lin KL. Therapeutic hypothermia associated with increased survival after resuscitation in children. Pediatr Neurol 2013; 48:285-90

97. Bennett KS, Clark AE, Meert KL, et al; Pediatric Emergency Care Medicine 
Applied Research Network. Early oxygenation and ventilation measurements after pediatric cardiac arrest: lack of association with outcome. Crit Care Med 2013; 41:1534-42.

98. Guerra-Wallace MM, Casey FL 3rd, Bell MJ, Fink EL, Hickey RW. Hyperoxi and hypoxia in children resuscitated from cardiac arrest. Pediatr Crit Care Med 2013; 14:e143-8.

99. Del Castillo J, López-Herce J, Matamoros M, et al; Iberoamerican Pediatric Cardiac Arrest Study Network RIBEPCI. Hyperoxia, hypocapnia and hypercapnia as outcome factors after cardiac arrest in children. Resuscitation 2012; 83:1456-61.

100. Ferguson LP, Durward A, Tibby SM. Relationship between arterial partial oxygen pressure after resuscitation from cardiac arrest and mortality in children. Circulation 2012; 126:335-42.

101. Topjian AA, French B, Sutton RM, et al. Early postresuscitation hypotension is associated with increased mortality following pediatric cardiac arrest. Crit Care Med 2014; 42:1518-23.

102. Lin YR, Li CJ, Wu TK, et al. Post-resuscitative clinical features in the first hour after achieving sustained ROSC predict the duration of survival in children with non-traumatic out-of-hospital cardiac arrest. Resuscitation 2010; 81:410-7.

103. Lin YR, Wu HP, Chen WL, et al. Predictors of survival and neurologic outcomes in children with traumatic out-of-hospital cardiac arrest during the early postresuscitative period. J Trauma Acute Care Surg 2013; 75:439-47.

104. Haque IU, Zaritsky AL. Analysis of the evidence for the lower limit of systolic and mean arterial pressure in children. Pediatr Crit Care Med 2007; 8:138-44.

105. Zubrow AB, Hulman S, Kushner H, Falkner B. Determinants of blood pressure in infants admitted to neonatal intensive care units: a prospective multicenter study. Philadelphia Neonatal Blood Pressure Study Group. J Perinatol 1995; 15:470-9.

106. Kleinman ME, Chameides L, Schexnayder SM, et al. Part 14: pediatric advanced life support: 2010 American Heart Association Guidelines for Cardiopulmonary Resuscitation and Emergency Cardiovascular Care. Circulation 2010; 122(18 Suppl 3):S876-908.

107. Kessler SK, Topjian AA, Gutierrez-Colina AM, et al. Short-term outcome prediction by electroencephalographic features in children treated with therapeutic hypothermia after cardiac arrest. Neurocrit Care 2011; 14:37-43.

108. Nishisaki A, Sullivan J 3rd, Steger B, et al. Retrospective analysis of the prognostic value of electroencephalography patterns obtained in pediatric in-hospital cardiac arrest survivors during three years. Pediatr Crit Care Med 2007; 8:10-7.

109. Abend NS, Topjian AA, Kessler SK, et al. Outcome prediction by motor and pupillary responses in children treated with therapeutic hypothermia after cardiac arrest. Pediatr Crit Care Med 2012; 13:32-8.

110. Fink EL, Berger RP, Clark RS, et al. Serum biomarkers of brain injury to classify outcome after pediatric cardiac arrest. Crit Care Med 2014; 42:664-74.

111. Topjian AA, Lin R, Morris MC, et al. Neuron-specific enolase and S-100B are associated with neurologic outcome after pediatric cardiac arrest. Pediatr Crit Care Med 2009; 10:479-90.

112. Topjian AA, Clark AE, Casper TC, et al; Pediatric Emergency Care Applied Research Network. Early lactate elevations following resuscitation from pediatric cardiac arrest are associated with increased mortality. Pediatr Crit Care Med 2013; 14:e380-7. 


\section{ANNEX}
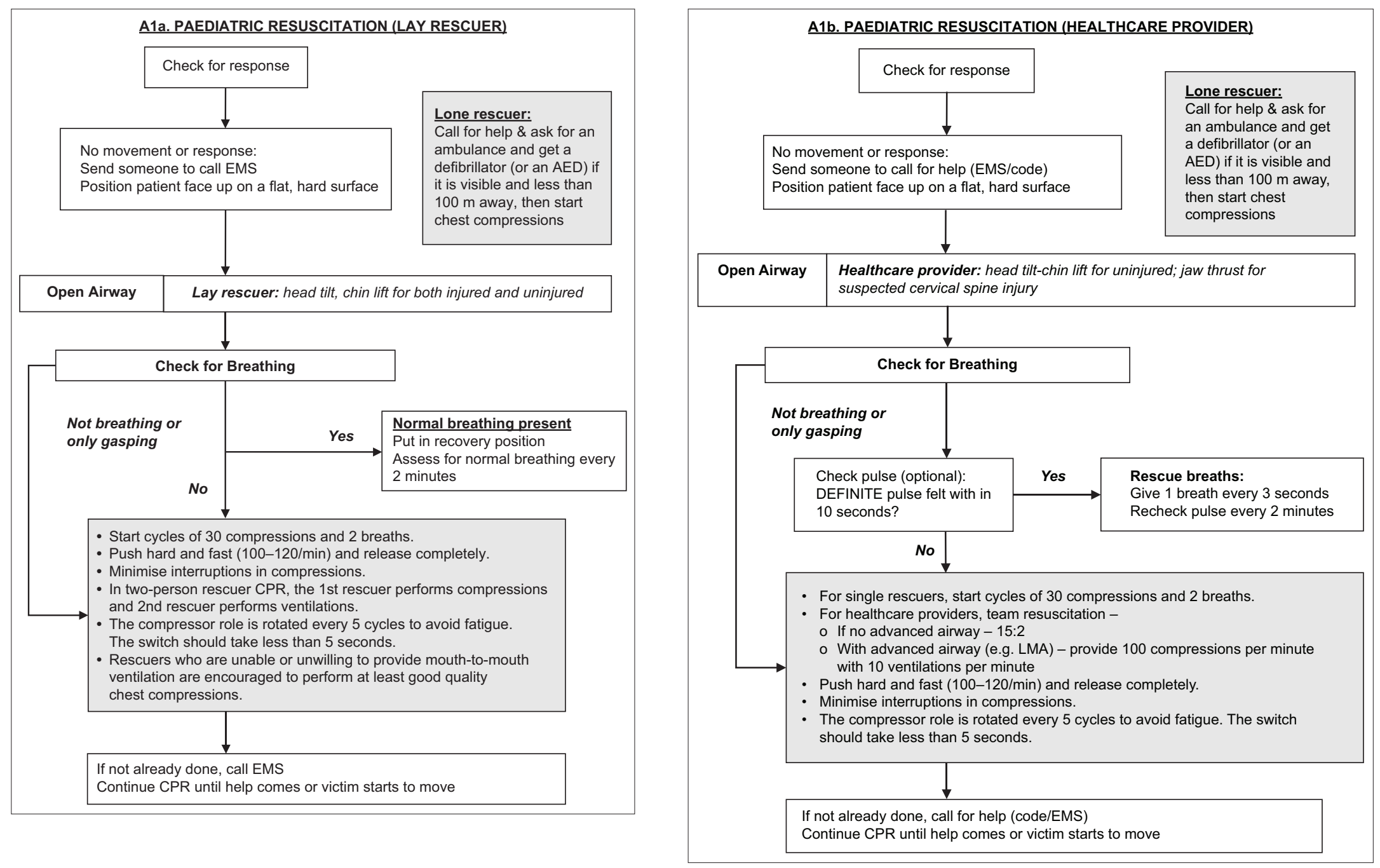

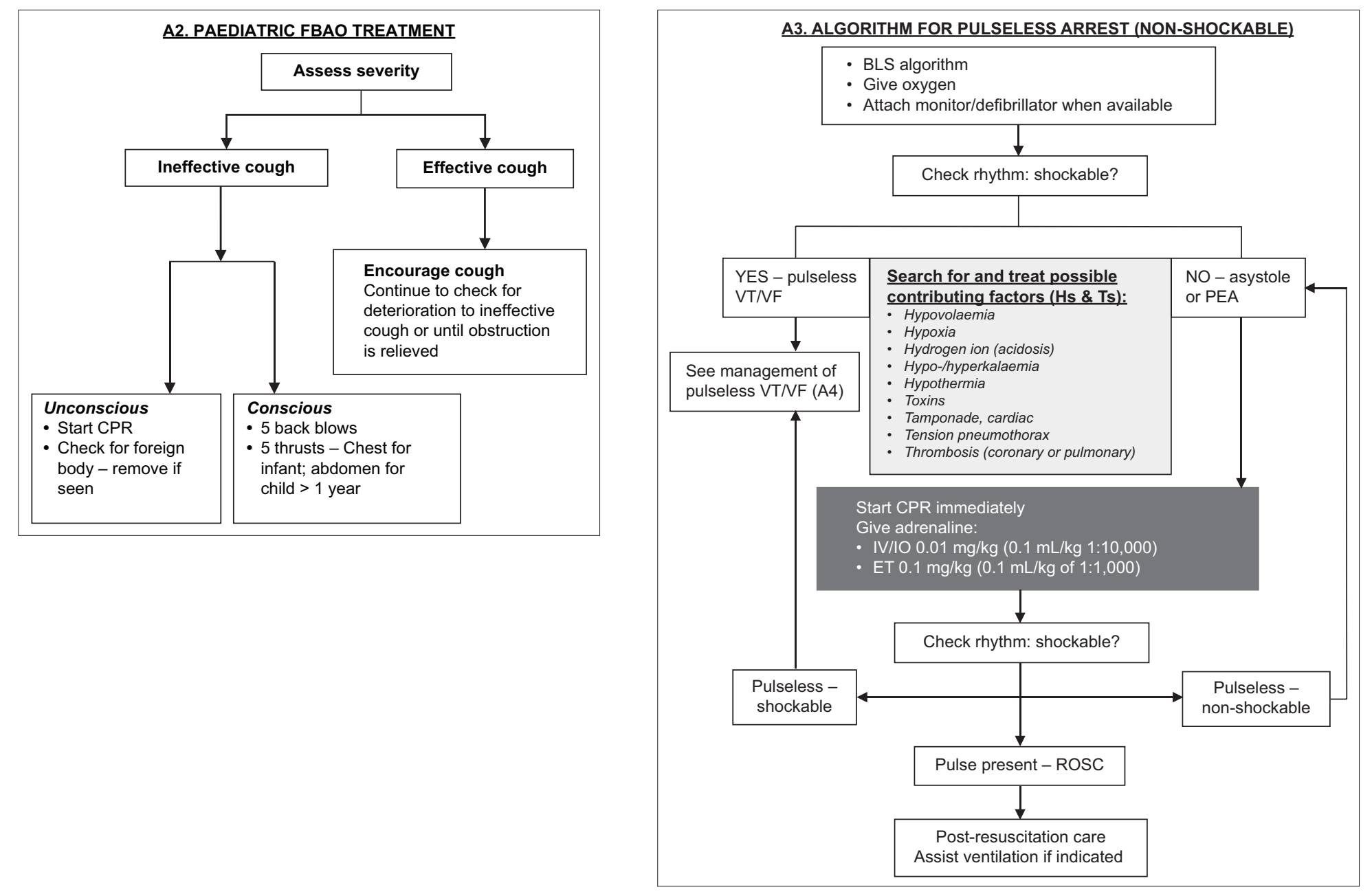

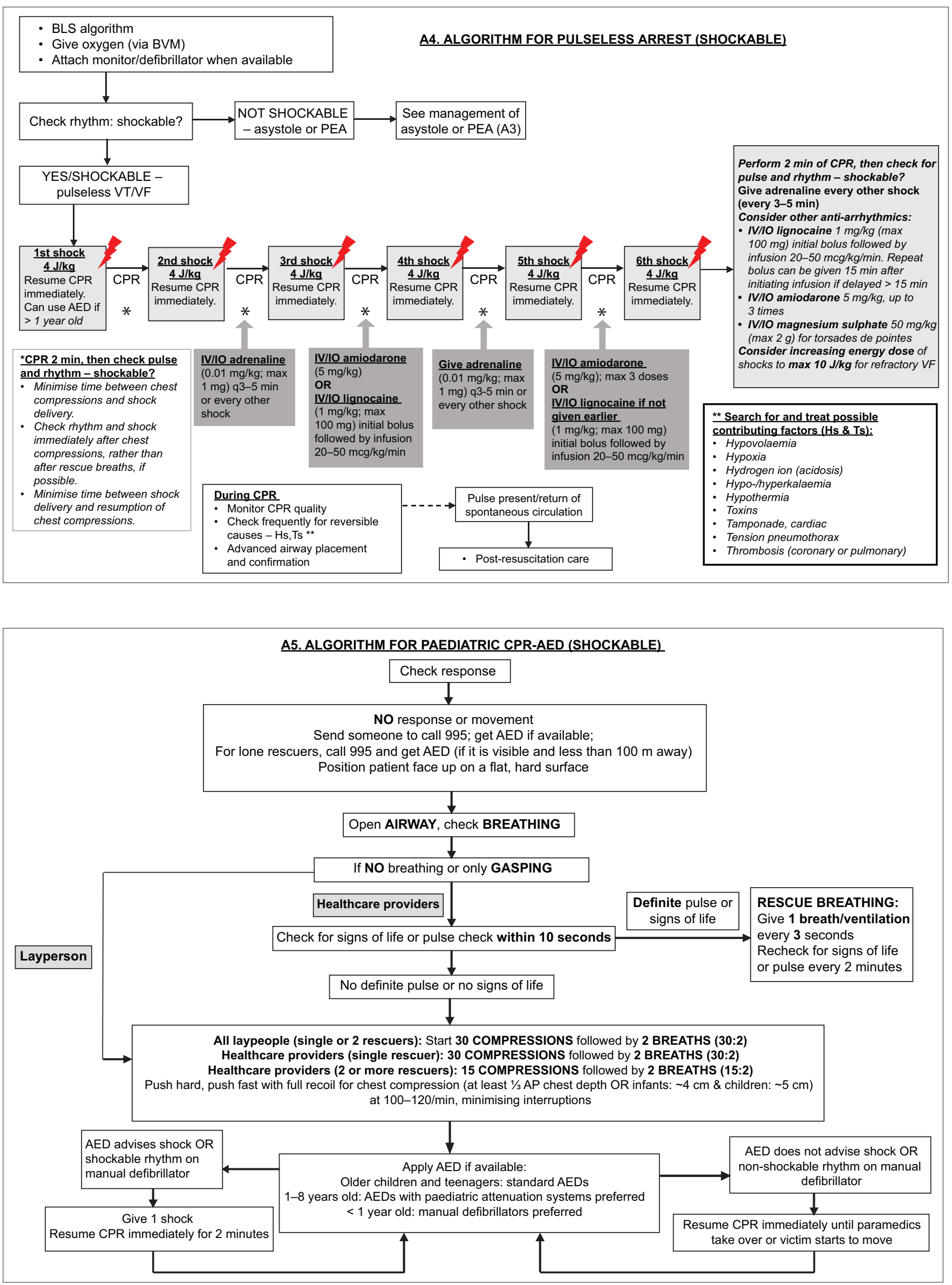


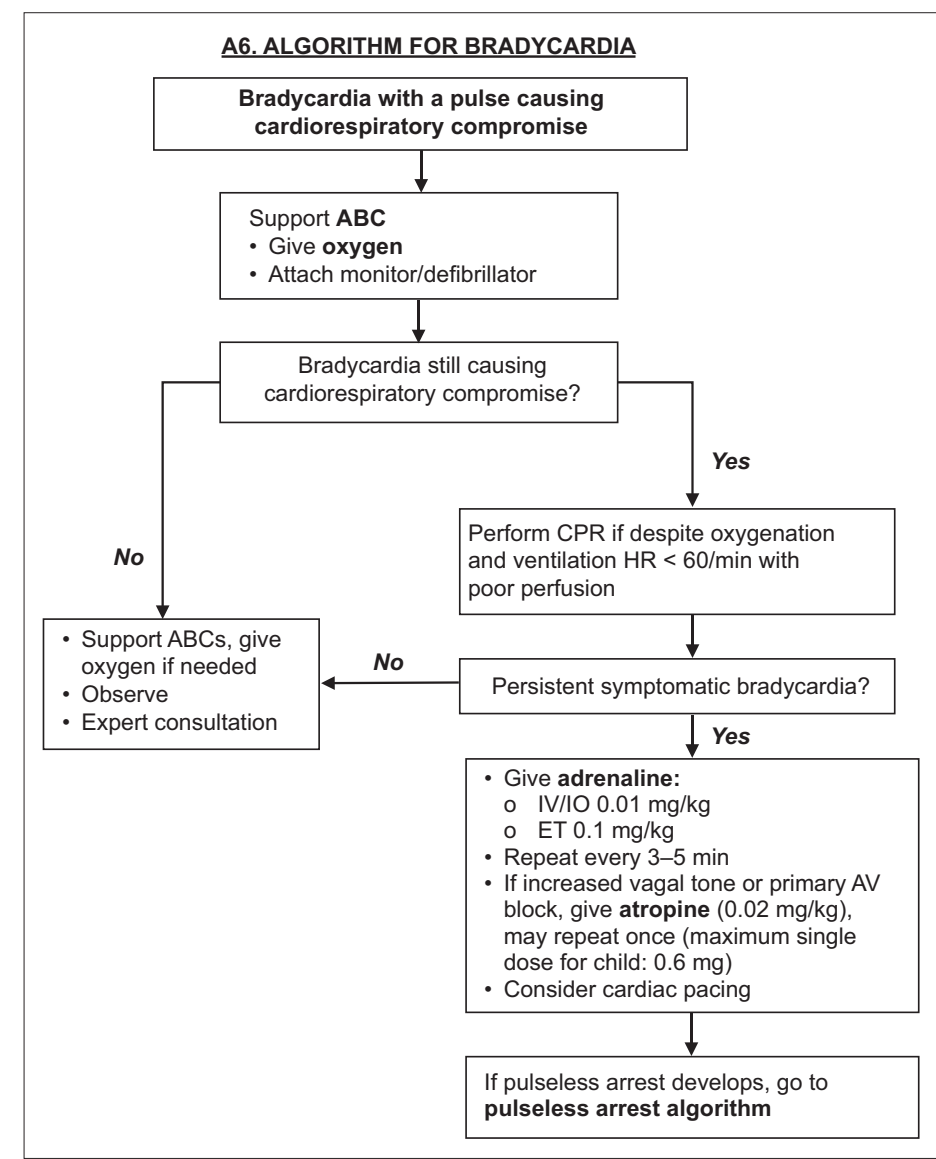

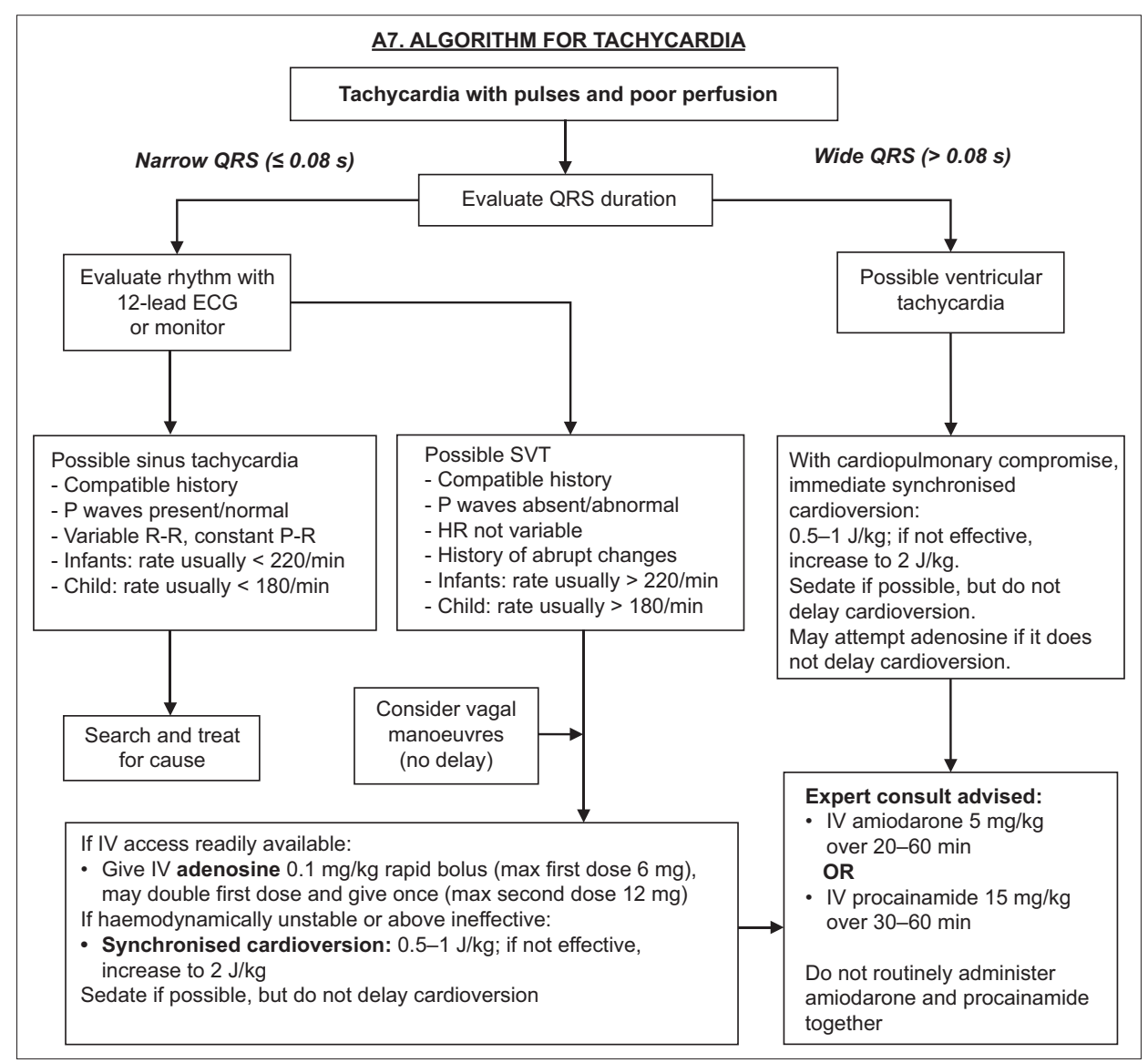

